\title{
De como a comunicação choca, revela, nos traz de volta ao mundo. Sobre 0 contato com a alteridade dentro e fora das tecnologias comunicacionais
}

Ciro Marcondes Filho

\section{Resumo}

0 ensaio estuda várias formas de comunicação e seu impacto sobre os que delas participam. Fala-se da cidade, dos movimentos de rua, das exposições. São diversas aplicações do procedimento metapórico aplicado à fotografia, ao cinema, aos documentários e aos vídeos pornôs da internet. Geralmente, a constatação é a de que esses produtos revelam coisas inusitadas, provocam choques e alterações, até mesmo uma retração no ato de falar sobre elas.

\section{Palavras-Chave}

Cidade. Movimentos de rua. Fotografia. Cinema. Documentários. Vídeos pornôs. Walter Benjamim.
Ciro Marcondes Filho I cjrmfilh@usp.br Doutor em Sociologia da Comunicação pela Universidade Johann Wolfgang Goethe (Alemanhã) e pós-doutor pela Universidade Stendhal de Grenoble (França). Professor Titular da Escola de Comunicações e Artes da USP, coordenador do FiloCom Núcleo de Estudos Filosóficos da Comunicação.

\section{A comunicação das cidades}

Processos de comunicação não são

necessariamente vinculados de forma direta aos grandes meios de comunicação, aos quais somos submetidos diariamente pela televisão, imprensa, publicidade, etc. Tampouco restringem-se aos contatos presenciais, físicos, entre pessoas, ou aos contatos eletrônicos. Há formas de comunicação menos exploradas, mas igualmente incidentes sobre nós, das quais pouco nos damos conta. A cidade é um exemplo disso. Quase ninguém pensa a cidade como um grande meio de comunicação, porque imagina sempre a comunicação acontecendo entre pessoas ou agentes que buscam exercer a ação, um sobre o outro. Mas a cidade exerce sobre nós uma ação mais sutil, porém não menos eficaz. As construções urbanas sofisticadas, a organização do espaço físico preservando ou não uma forma de habitar mais saudável, a arrogância de certas avenidas e edifícios, tudo isso constitui uma linguagem, uma forma de expressão, uma maneira de as ideologias dos arquitetos e de seus financiadores falarem através dos objetos e, 
com isso, expressarem ideias, visões de mundo, concepções do Outro. A cidade fala, informa sobre si mesma. Ela tem personalidade, ela demarca posições e limites.

Outro processo comunicacional pouco estudado como "comunicação" são os movimentos políticos urbanos. 0 Brasil viveu, em 2013 e 2014, ondas expressivas de movimentos de ruas. Em junho de 2013, as passeatas, convocadas pela internet, foram levando, semana após semana, a um fortalecimento da pressão política contra os governantes, permitindo o aparecimento de um novo ator político na cena dos grandes debates nacionais: a própria passeata. Esse fato, tanto no Brasil como no exterior, rompeu com vários anos, décadas até, de imobilismo na política, fato esse que era apontado por muitos como o desaparecimento do social das ruas. Ao contrário, as redes eletrônicas recuperaram as ruas e as tornaram um grande meio de comunicação para protestar.

0 interessante, no caso, é conhecer 0 que a vivência dessas manifestações produz em cada pessoa que sai às ruas ao acompanhar a marcha de protesto. Que estranho processo interno se desenvolve quando a pessoa troca seu quarto, sua sala, seu escritório, onde ficava o tempo todo diante de uma tela, pela rua, inicialmente para assistir à passagem do povo gritando palavras de ordem, depois misturando-se a ele, caminhando junto, fazendo uma verdadeira imersão no fluxo humano. Efetivamente, há um choque, uma quebra, um "click", que coloca o observador na posição de cobaia. Nós nos observamos observando a massa que passa. Nós sentimos a diferença, nós sentimos mudança. A massa de protesto nos comunica.

Em 2014, durante as campanhas presidenciais no Brasil, dois partidos radicalizaram seu afrontamento. Separadamente, convocaram 0 povo para as ruas, para fazer valer suas posições políticas, fossem elas mais sintonizadas com a esquerda, fossem elas mais simpatizantes da social-democracia. Alguns estudantes universitários realizaram, sob minha orientação, estudos comunicacionais dos movimentos de rua, buscando, precisamente, avaliar em si próprios os efeitos comunicacionais das passeatas. Frequentaram concentrações dos dois partidos políticos oponentes, procurando colocar-se o mais possível de "espírito aberto" para não interferirem nas impressões recebidas pelo movimento social.

Uma primeira sensação foi a confirmação do que Georges Bataille falava sobre essa "experiência interior", que é estar envolvido em uma cena de euforia, entusiasmo, paixão coletiva, fazendo nossa mente sair da indiferença cotidiana. Bataille era particularmente interessado nos fenômenos que conduziam ao "extremo possível do homem", no caso, os sacrifícios, a paixão, o ápice sexual, em que há arrebatamento, delírio, encantamento e êxtase. Certos tipos de transes ou "viagens" podem ser sentidos, também, em espetáculos futebolísticos, em touradas, e - por que não? - em passeatas de rua. A coisa se dá sem palavras, é um 
puro sentir; tratava-se, para ele, de uma vivência do sagrado, experiência meramente antropológica, sem qualquer conotação com a religião. Como dizia ele, o espírito só pode expor-se quando cessam as operações intelectuais de entendimento e compreensão.

Foi mais ou menos o que vivenciaram os estudantes que assistiram nas ruas às manifestações, que se estenderam inclusive no transporte público. Na avenida, a sensação era de que ela, a própria avenida, estava sendo inteiramente "dominada", diz uma pesquisadora [Iaconis, in: Coutinho, 2014, p. 14]. Mas a rua continuava para dentro do metrô, em que, em seu interior, as pessoas, mais próximas fisicamente, vivenciavam essa energia contagiante abrindo mão de seu fechamento, de seu isolamento. "Apesar de não se conhecerem, senti, no metrô, que as pessoas sentiam-se conhecidas" [Freitas, 2014, p. 4]. Esse tipo de emoção provoca uma sensação equivalente aos momentos de emoção cívica, compartilhada, comum, que ocorre na execução e no canto coletivo do Hino Nacional.

A vivência das passeatas trouxe, segundo as observadoras, dois tipos de sensações novas: a de terem sido verdadeiramente "tocadas" pela passeata e a de quebra de preconceitos e estereótipos relativos a demonstrações. Heloisa sentiu que sua mãe, que a acompanhava e estava muito resistente, em um certo momento foi, ela também, envolvida pela atmosfera do protesto [Iaconis, in: Coutinho, 2014, p. 16]. Para ela, mesmo não concordando necessariamente com 0 motivo de cada manifestação, essa vivência tem sempre algo a acrescentar a quem dela participa [Coutinho, 2014, p. 11]. Ela declarou que mudou sua forma de encarar os protestos [Iaconis, in: Coutinho, 2014, p. 16]. 0 termo "força popular" ganhou, segundo sua observação, um sentido inteiramente novo: "real, palatável, possível de ser sentido" [idem, p. 13].

\section{Da rua à galeria}

A cidade é também espaço de exposições, momento em que as pessoas param de trabalhar e vão buscar um entretenimento diferente, uma "abertura do espírito". Mas, às vezes, são também formas de choque. A exposição "Operação Condor", realizada na Universidade de São Paulo (USP), em 2014, fala das atrocidades cometidas pela ditadura militar brasileira e pretende, com ela, retirar 0 visitante da sua tranquilidade, transportando-0 para o sinistro mundo do terror político. Não trata apenas de uma emoção fictícia e cheia de adrenalina, como nos videogames; é a tentativa de evocar politicamente, no visitante, o mal-estar de uma época. Especialmente por meio de fotografias.

A fotografia é, de qualquer forma, um misterioso meio de comunicação. Ela não nos conduz, levando-nos pela mão, ao desenrolar de uma ação. Se o cinema é uma narrativa horizontal, a fotografia, por não ser movimento, é uma incursão vertical. Ela nos faz parar. E ver. É nossa fantasia de - e estimulada a - imaginar a cena, as pessoas, 
o mundo por trás dela. Trata-se de uma parada reflexiva. Quase uma meditação. E por não ser uma pintura, obra deliberada de um autor, e ser, ao contrário, efeito de uma situação externa não necessariamente controlada, a fotografia enfeitiça, enquanto o cinema nos embala.

Em uma exposição com tema político, é preciso reter a atenção. Diz Beatriz que "algumas fotos são longamente exibidas mais com o propósito de tocar, de alguma forma, o espectador.

Determinadas fotos puderam exercer um tipo de forte sensação sobre nós e nos deixar pairando entre 0 silêncio da dor e a indecifrável música de fundo para que pudéssemos apreendê-las" [Camargo, 2014, p. 5].

Com efeito, no cinema, a combinação de música e imagem em movimento tem potencial de emoção para conduzir à entrega e à imersão na cena. Uma foto acrescida de um acompanhamento sonoro, musical, pode, em certos casos, ter ainda mais força. Essa é a vantagem de algumas exposições contemporâneas que buscam nos transportar para a cena, efeito que a música sempre conseguiu, e sem muito esforço, nos transportando para épocas e cenários jamais vividos, mas densamente apreciados. E Beatriz emocionou-se. A foto tocou-a. A fez sentir-se "não como uma mera espectadora mas quase como uma amiga com quem partilhava aqueles momentos" [Camargo, 2014, p. 6].

Existe a fotografia, reprodução muda de pessoas e cenas. Existe um som que pode ser agregado à foto para aumentar a densidade emocional. Mas pode existir também o texto explicativo. Em alguns casos de pintura, especialmente as formas abstracionista, conceitual, concreta, os textos são inteiramente dispensáveis. Em muitos casos, afunilam a percepção, reduzem o campo semântico. Mas há situações em que 0 texto dá vida à foto. Alguns visitantes dessa exposição "muitas vezes olhavam a fotografia com neutralidade mas quando liam a legenda seus rostos automaticamente mudavam" [Spolle, in Quandt, 2014, p. 14-15].

Algumas pessoas saíam "iluminadas", dizendo que "naquele momento, haviam entendido, de forma verdadeira, a dimensão daquele acontecimento" [Nepomuceno, in: Quandt, 2014, p. 23]. Outras, realmente muito afetadas, chegavam mesmo a desmaiar diante da força dessas imagens. "Minha tia ficou muito impressionada. Iria pensar naquilo durante toda a semana. Vira e mexe volta a pensar nesse período tenebroso. Mudou muito sua forma de pensar sobre a época" [Spolle, in Quandt, 2014, p. 18]. A visita à exposição deixava de ter caráter meramente lúdico para abalar internamente a paz dos visitantes, efeito esse que não é conseguido (possivelmente, nem tentado) em outros espaços historicamente marcados por sofrimento, tortura e dor, como alguns campos de concentração europeus.

Mas o mal-estar com a fotografia pode ocorrer também quando nos deparamos com fotos que escapam do trivial e do publicitariamente 
promovido e nos colocam cara a cara com aquilo que normalmente evitamos. Yossi Loloi publicou em seu Fullbeauty Project fotos de mulheres nuas, extremamente obesas, em poses eróticas. Um de nossos pesquisadores, ao deparar-se com essas imagens, chocou-se consigo mesmo, ao sentir asco. Para ele, "a estranheza se traduzia em repulsa" [Sakaguti, in Pereira, 2014, p. 4)]. Mas, ao mesmo tempo, era uma importante revelação: "0 ensaio me surpreende profundamente, evidencia minha irracionalidade, mostra que sou menos aberto do que realmente [achava que] era, menos humanista, mais convencional e conservador do que pensava... Senti asco de mim mesmo. Esse 'monstro' que eu vejo me mostra o quanto eu mesmo sou repugnante e monstruoso" [idem, p. 5 (11)].

Outros estudantes dedicaram-se a outros conjuntos de fotografias, mas que, igualmente, nos questionam sobre os modelos de beleza que filtram nosso olhar e os direcionam apenas àqueles corpos esteticamente corretos. Observando tribos africanas, Sakaguti constata, em Cadernos etíopes, de Josep Rouaix Duran, que rostos deixam escapar uma certa ambiguidade, mostrando que nós, homens e mulheres, em realidade, somos muito parecidos [Sakaguti, in Pereira, 2014, p. 10]. Outra pesquisadora, Beatriz Pereira, refletiu sobre as fotografias, pensando qual dos componentes do ensaio de Alvin Booth, Osmosis, iria escolher, quando se deu conta de que o único sobre 0 qual ela não gostaria de falar era precisamente aquele sobre o qual mais "deveria" falar: "ele foi o que mais me feriu, me fez pensar, me perturbou realmente..." [Pereira, 2014, p. 15].

Há fotos de obesas, de sociedades tribais, fotos eróticas. Mas há o nu, aquilo que nos iguala a todos em nossa mera materialidade carnal, isenta das representações embutidas nas roupas, nas tatuagens e nas maquiagens. Nas fotos de nudez, talvez como metáfora do rosto como canal que nos remete ao Infinito, de Levinas, "pode se ver a humanidade de todas as pessoas, sem restrições, sem ocultamento" [Santos, in Pereira, 2014, p. 7].

\section{Filmes e cumplicidade}

No entanto, filmes também possuem sua magia, sua força comunicacional. Pedro Meyer montou em 1991, e depois, em 2007, a conhecida sequência de fotografias que narra 0 desaparecimento de seus pais em I Photogragh to Remember. Aqui, particularmente, as fotos necessitam do som, como na exposição 0peração Condor, para aumentar sua força: "Sem a voz, a obra não teria 0 mesmo valor emotivo e o mesmo poder de sensibilização. Não creio que as imagens fossem capazes de dizer por elas mesmas tudo o que a alma e o coração do filho tinha a dizer" [Camargo, 2014, p. 4].

Filmes podem chocar como as exposições que buscam reconstruir a cena do terror. Algumas imagens de Nuit et brouillard, de Alain Resnais, 1955, jamais poderão ser esquecidas. 
Resnais constrói um documentário filmando fotos, juntando trechos originais de campos de concentração, narrando fatos bizarros, chocantes, aterradores. Mas as cenas, as cenas nos levam muito mais longe. Porque 0 documentário tem a vantagem de trabalhar com o "realmente vivido", com a monstruosidade em sua forma mais nua. Um filme do mesmo tipo foi o Come and See, de Elem Klimov, 1985, o qual relata o pânico do jovem Florya diante da marcha nazista sobre sua cidade. Diz Barbara Monfrinato, "durante a noite, sonhei com o filme. A primeira imagem que surgiu na minha cabeça quando acordei, no dia seguinte, foi o rosto de Florya olhando para mim. Me pego com essa imagem até hoje" [Monfrinato, 2014, p. 5-6].

0 documentário, neste caso, não trata de um tema de forma distanciada. Os olhos dos personagens voltam-se ao espectador, como quem espera alguma atitude. "Os rostos. Eles olham diretamente para a câmera, encarando 0 espectador, envolvendo-o na história, muitas vezes reforçando o papel de testemunha e cúmplice dos fatos... Isso gera um intenso acontecimento comunicacional e provoca uma revisão das cenas passadas" [Souza in Monfrinato, 2014, p. 11].

\section{A alteridade nas cidades, na manifestação, nos rostos}

Alguns rapazes resolveram aceitar o desafio de Walter Benjamin: perder-se em uma cidade. Não é tão sério não encontrar seu caminho em uma cidade, dizia ele, mas, para se perder, como a gente se perde em uma mata, para isso é preciso aprendizado [Benjamin, W., 1950]. A mata nos ensina de uma forma não sígnica, não linguística. Galhos secos estalando funcionam como nomes de ruas, diz ele, o vale na montanha lhe indicará as horas do dia.

É uma outra forma de ouvir a cidade. Atentar para seus acordes, sua melodia, apreciar seu desenho, como se fosse a linguagem da natureza. Um dos pesquisadores apanhou ao acaso um ônibus e foi conhecendo visualmente os bairros urbanos, até 0 ônibus fazer o ponto final no interior de uma favela. Sentiu pânico. Deu meiavolta e tomou o mesmo ônibus novamente. Ao cabo de todo um período de andanças ao léu por lugares estranhos e desconhecidos, deparouse com a estação Marechal Deodoro do metrô e sentiu-se feliz. "Não sou mais um forasteiro, frágil..." [Andrade, in Bernardo, 2014, p. 13].

A cidade encanta, mas também assusta. Às vezes, optamos por não ver. Recusamos a comunicação. 0 Outro nos incomoda. É uma alteridade com a qual somos confrontados. Porém, fugir dela nos mata, diz Maria Teresa: "0 que mata muitas vezes é não ver ou não querer ver... Sinto que hoje, depois de visitar o Memorial da Inclusão, sou mais pessoa do que ontem. A visita mexeu comigo e quando algo mexe conosco não devemos ignorar ou agir de forma racional... Devemos prosseguir emocionalmente, quase de olhos fechados" [Cardigos, in Mihaltchuk, 2014, p. 10]. 
De olhos fechados é como o caminhar pela mata, de Benjamin. É 0 acompanhar das passeatas políticas, vivenciando-as de perto: "Ir aos protestos de rua foi um ótimo exercício para treinar não julgar os outros, suas diferentes posições políticas e reivindicações" [Iaconis, in Coutinho, 2014, p. 16]. Ou conhecer um pouco mais da vida dos moradores de rua: "internamente, eu os via como incapazes de racionalização. As roupas, 0 modo de falar e as perguntas do repórter mostram como somos ignorantes perante esses homens" [Tubone, 2014, p. 8].

Tal qual as fotos de homens e mulheres etíopes, as ideias do morador de rua, "mais do que me surpreender, provocaram em mim certa identificação. As pessoas são mais parecidas comigo do que eu jamais poderia imaginar...", diz Sofia Mendes [Tubone, 2014, p. 9]. Ou as histórias de Eduardo Coutinho, no documentário "As canções", 2011, que eram cômicas "e eu enxergava ali a riqueza da existência humana... Contemplei a vida humana que se desenrola e passa ao largo de quase todas as análises, em especial, no jornalismo" [Souza, in Monfrinato, 2014, p. 16].

\section{Os meios digitais}

A alteridade na era digital se mostra por outros meios. É menos possível a imersão, e, portanto, a vivência plena do Outro - pessoa, objeto ou acontecimento - que se coloca à nossa frente. $\mathrm{Na}$ rede, há dois tipos de Outro: 0 outro conhecido e 0 outro desconhecido. Com o primeiro, relacionamo- nos de forma complementar: as mensagens, as fotografias, os arquivos mandados complementam um relacionamento offline, geralmente não dissonante. "Defrontamo-nos", de fato, com uma alteridade radical ou semirradical quando outro nos provoca, mexe com nossa estabilidade.

Alguns de nossos pesquisadores estudaram as manifestações de ódio na internet, especialmente nesse ano (2014), em que as eleições brasileiras foram fortemente marcadas pela emocionalidade, pela violência verbal e física, pelas manifestações inescrupulosas de instigação à estupidez, à violência e ao crime. "Lendo discursos sobre 0 ódio, senti vontade de responder na mesma altura”, diz Jeferson Gonçalves [Gonçalves, 2014, p. 3]. "Ao ver 0 vídeo, senti que Levy Fidelix fazia ofensas e ataques diretamente a mim; o discurso de Levy Fidelix conversou diretamente comigo, diz outro pesquisador" [Nona, in Gonçalves, 2014, p. 9]. 0 recrudescimento do conservadorismo moral levou este país à naturalização e à banalização da violência, especialmente em relação à comunidade LGBT, fato esse que atingiu profundamente 0 próprio pesquisador.

0 Outro, mediado eletronicamente, ocupou, neste caso, o papel de um provocador presente, fisicamente desafiador, incitador. Não é um fato comum na internet, que mais comumente se presta a amenidades. No caso, 0 candidato à presidência da República, fazendo propaganda do ódio e da repressão às minorias, instigou nosso pesquisador à contrarreação, ao 
enfrentamento, ao choque. A confrontação

com o Outro radical, pode-se dizer, ocorreu dos dois lados, disseminando ódio e respostas emocionalmente irracionais. Não se pode dizer que houve, tecnicamente, "comunicação", visto que mensagens de agressão funcionam, ao contrário, para preservação de uma situação que estaria supostamente ameaçada. Sai-se à luta pela manutenção de certa posição e pela preservação de pontos de vista.

A internet foi utilizada nessa época de acentuado acirramento político e ideológico para bombardear adversários com ideias racistas, segregacionistas, preconceituosas e estimuladoras da violência.

Para Ulysses Faria, "não há comunicação desses temas nas redes sociais. Todos se manifestam com um pensamento já pronto" [Faria, in Gonçalves, 2014, p. 13].

Caso bastante diferente é a influência dos vídeos pornográficos na internet e de como eles alteram a estabilidade sexual do espectador, mutilando suas próprias elaborações pessoais.

Milano relata 0 caso de um espectador - seu pesquisado - que assistia a um vídeo em que na cena representava-se uma situação erótica entre um homem e uma mulher vestida de enfermeira. "No vídeo, uma mulher com roupa de enfermeira. Ele pensava na única garota com a qual tinha se relacionado sexualmente e projetava a cena com ela... Criavam-se novas fantasias sexuais em sua mente, novos fetiches. Pensou até que sua própria sexualidade estava sendo transformada. Começava a desejar os dois, não apenas a mulher. Desejava 0 ato" [Milano, in Aguiar, 2014, p. 5-6].

Para ele, 0 vídeo pornográfico teria uma forte capacidade de envenenar sua própria memória anterior. Diz seu pesquisado que "a cena lhe instigava memórias reais. Ele não estava mais excitado apenas com o pornô. Estava excitado com sua memória. Memórias que percebeu estarem sendo deturpadas pela cena... Cena essa que se projetava em suas lembranças, inserindo-se em suas memórias. Pensou que suas relações sexuais, passadas e futuras, agora estavam sendo contaminadas pela pornografia" [idem, p. 6]. Seu sentimento começava a ficar embaralhado: "Era um sentimento confuso, dúbio, angustiante. Não queria desejar sua ex-namorada. Não queria desejar a atriz. Não daquela forma. Não queria mais sentir algo que não poderia controlar. Cada vez que assistia a um pornô e lembrava-se de sua ex-namorada, achava que suas memórias estavam sendo vulgarizadas. Que sua vida sexual era vulgar. Que sua saudade passava a ser física e não mais sentimental" [idem, p. 6].

0 espectador, estudado pelo nosso pesquisador, não queria sentir algo que não poderia controlar. Os vídeos eróticos têm essa particularidade. Não criam apenas hábitos, vícios, como os videogames. Não são lúdicos, ingênuos, brincalhões como as páginas pessoais do Facebook. Não são espaços de conversa, de obtenção de informação, de busca acadêmica. Eles desnudam um universo até 
então exclusivo, fechado, íntimo, frágil mesmo, mostrando, da forma mais descarada e pervertida, a sexualidade humana em sua rudez primária.

A alteridade, no caso, não se conforma, ao contrário, age como agente deformador. Por ser um campo ao mesmo tempo mitificado e, por isso, visceralmente aberto ao voyeurismo, o pornô invade territórios do psiquismo até então pouco resguardados da violência e da capacidade de intrusão do Outro. Talvez, especialmente para a sexualidade masculina, público-alvo por excelência desses vídeos, ela encontra um campo de afirmação sexual mais fragilizada, tendo, por isso, a capacidade de pôr em xeque sexualidades constituídas.

Pelo menos foi isso o que o pesquisador constatou em seu pesquisado, a ausência de âncoras, de bases de fixação de sua identidade sexual, provocando, contrariamente, um verdadeiro pânico diante de algo que sentia, mas não podia controlar. Uma comunicação bem-sucedida, mesmo que perversa.

\section{Referências}

AGUIAR, Matheus P. de [2014]; MILANO, Leonardo R. "Relatos de uma experiência pornográfica". In: Festival Metapórico 5a ${ }^{\text {a }}$ Edição, Arquivo FiloCom, ECA-USP, São Paulo, 2014.

BATAILLE, Georges [1943]. A experiência interior. Trad. Celso Libânio Coutinho, Magali Montagné, Antonio Ceschin. São Paulo, Editora Ática, 1992.
BATAILLE, Georges [1957]. 0 erotismo. Trad. Cláudia Fares. São Paulo, ARX, 2004.

BENJAMIN, W. [1950] Berliner Kindheit um Neunzehnhundert (A infância berlinense por volta de 1900). In: http://gutenberg.spiegel.de/buch/st-2983/6.

BERNARD0, Leandro dos S. [2014]; SACRAMENTO, Matheus M.; ANDRADE, Vitor M. de, "A comunicação de São Paulo: o metáporo do desconhecido". In:

Festival Metapórico 5a . Edição, Arquivo FiloCom, ECA-USP, São Paulo, 2014.

CAMARG0, Beatriz N.[2014]; SCHEMPP, Isabella; RICARD0, Jean; GIACOBELLI, Juliana; VALIM, Matheus "Sobre a vivência e a apreensão da ferida aberta de Outrem". In: Festival Metapórico 5a . Edição, Arquivo FiloCom, ECA-USP, São Paulo, 2014. COUTINHO, Dimitria [2014]; IACONIS, Heloisa; GALANTE, Isabella; DARC, Joana. "Uma pesquisa metapórica acerca de protestos políticos. Um olhar-míssil contra a estabilidade". In: Festival Metapórico 5 ${ }^{\text {a }}$ Edição, Arquivo FiloCom, ECA-USP, São Paulo, 2014.

FREITAS, Juliana B. De [2014], "Olê, olê, olê, olá, Dilma!” In: Festival Metapórico 5a . Edição, Arquivo FiloCom, ECA-USP, São Paulo, 2014.

GONÇALVES, Jeferson [2014]; HIMMELSTEIN, Laura; NONA, Marcos V.; FARIA, Ulysses e ALMEIDA, Vinicius. "Contra tudo e contra todos: 0 discurso do ódio e 0 ato comunicacional”. In: Festival Metapórico 5a . Edição, Arquivo FiloCom, ECA-USP, São Paulo, 2014.

MIHALTCHUK, Maria [2014]; CARDIGOS, Maria Teresa. "Um mundo invisível aos sentidos. Visita ao memorial da inclusão". In: Festival Metapórico 5a . Edição, Arquivo FiloCom, ECA-USP, São Paulo, 2014.

MONFRINATO, Barbara [2014], M. F; SOUZA, Guilherme F. de. "Relatos de imagens (selecionadas) em movimento: uma experiência metapórica". In: Festival Metapórico 5a . Edição, Arquivo FiloCom, ECA-USP, São Paulo, 2014. 
PEREIRA, Beatriz R. [2014]; SANTOS, Kaio C.

dos; LIMA, Letícia M. L. de; SAKAGUTI, Luiz H.,

"Êxtase fotográfico, desestabilização das convenções

corporais". In: Festival Metapórico 5a . Edição,

Arquivo FiloCom, ECA-USP, São Paulo, 2014.

QUANDT, Daniel T. [2014]; AUGUSTO, Isabela C.;

SPOLLE, Lana 0.; MESQUITA, Paula N. de, "A comu|

nicação na exposição ‘Operação Condor”'. In: Festival

Metapórico 5a . Edição, Arquivo FiloCom, ECA-USP,

São Paulo, 2014.

TUBONE, Daniel [2014]; LIMA, Isabel; MENDES,

Sophia. "Pesquisa do acontecimento comunicacional.

Documentário ‘Do outro lado da sua casa'”. In: Festival

Metapórico 5a . Edição, Arquivo FiloCom, ECA-USP,

São Paulo, 2014. 


\section{How communication shocks, reveals, and bring us back to the world. About the contact with the alterity inside and outside the communication technologies}

\section{Abstract}

The essay studies various forms of communication and its impact on those who participate in them. It is said about the city, street movements, the exhibits. There are several applications of the metaporic procedure applied to photography, cinema, documentaries and porn videos from the internet. Generally, the finding is that these products reveal unusual things, cause shocks and changes, even a retraction in the act of talking about them.

\section{Keywords}

Cities. Street movements. Photography. Cinema. Documentaries. Porn videos. Walter Benjamin.

\section{Como la comunicación choca,} revela, nos trae de vuelta al mundo.

\section{Sobre el contacto con la}

alteridad dentro y afuera de las tecnologias comunicacionales

\section{Resumen}

El texto está estudiando diversas formas de comunicación y su impacto en las personas que participan en ellos. Se habla de la ciudad, los movimientos de la calle, las exposiciones. Hay varias aplicaciones del procedimiento metapórico aplicado a la fotografía, el cine, documentales y videos porno de internet. En general, la conclusión es que estos productos revelan cosas inusuales, causan perturbaciones y cambios, incluso una retracción en el acto de hablar de ellos.

\section{Palabras clave}

Ciudad. Movimientos de calle. Fotografia. Cine. Documentários. Vídeos Pornos. Walter Benjamim. 


\section{Expediente}

A revista E-Compós é a publicação científica em formato eletrônico da Associação Nacional dos Programas de Pós-Graduação em Comunicação (Compós). Lançada em 2004, tem como principal finalidade difundir a produção acadêmica de pesquisadores da área de Comunicação, inseridos em instituições do Brasil e do exterior.

\section{E-COMPÓS I www.e-compos.org.br I E-ISSN 1808-2599}

Revista da Associação Nacional dos Programas de Pós-Graduação em Comunicação.

Brasília, v.18, n.1, jan./abri.. 2015.

A identificação das edições, a partir de 2008, passa a ser volume anual com três números.

\section{CONSELHO EDITORIAL}

Alexandre Rocha da Silva, Universidade Federal do Rio Grande do Sul, Brasil Alexandre Farbiarz, Universidade Federal Fluminense, Brasil Ana Carolina Damboriarena Escosteguy, Pontifícia Universidade Católica do Rio Grande do Sul, Brasil

Ana Carolina Rocha Pessôa Temer, Universidade Federal de Goiás, Brasil Ana Regina Barros Rego Leal, Universidade Federal do Piauí, Brasil André Luiz Martins Lemos, Universidade Federal da Bahia, Brasil Andrea França, Pontifícia Universidade Católica do Rio de Janeiro, Brasil Antonio Carlos Hohlfeldt, Pontifícia Universidade Católica do Rio Grande do Sul, Brasil

Arthur Ituassu, Pontifícia Universidade Católica do Rio de Janeiro, Brasil Álvaro Larangeira, Universidade Tuiuti do Paraná, Brasil Ângela Freire Prysthon, Universidade Federal de Pernambuco, Brasil César Geraldo Guimarães, Universidade Federal de Minas Gerais, Brasil Cláudio Novaes Pinto Coelho, Faculdade Cásper Líbero, Brasil Daisi Irmgard Vogel, Universidade Federal de Santa Catarina, Brasil Daniela Zanetti, Universidade Federal do Espírito Santo, Brasil Denize Correa Araujo, Universidade Tuiuti do Paraná, Brasil Eduardo Antonio de Jesus, Pontifícia Universidade Católica de Minas Gerais, Brasil

Eduardo Vicente, Universidade de São Paulo, Brasil

Elizabeth Moraes Gonçalves, Universidade Metodista de São Paulo, Brasil Erick Felinto de Oliveira, Universidade do Estado do Rio de Janeiro, Brasil Francisco Elinaldo Teixeira, Universidade Estadual de Campinas, Brasil Francisco Paulo Jamil Almeida Marques, Universidade Federal do Ceará, Brasil Gabriela Reinaldo, Universidade Federal do Ceará, Brasil Gisela Grangeiro da Silva Castro, Escola Superior de Propaganda e Marketing, Brasil

Goiamérico Felício Carneiro Santos, Universidade Federal de Goiás, Brasil Gustavo Daudt Fischer, Unisinos, Brasil

Herom Vargas, Universidade Municipal de São Caetano do Sul, Brasil
Itania Maria Mota Gomes, Universidade Federal da Bahia, Brasil Janice Caiafa, Universidade Federal do Rio de Janeiro, Brasil Jiani Adriana Bonin, Universidade do Vale do Rio dos Sinos, Brasil José Afonso da Silva Junior, Universidade Federal de Pernambuco, Brasil José Luiz Aidar Prado, Pontifícia Universidade Católica de São Paulo, Brasil Kati Caetano, Universidade Tuiuti do Paraná, Brasil

Lilian Cristina Monteiro França, Universidade Federal de Sergipe, Brasil Liziane Soares Guazina, Universidade de Brasília, Brasil Luíza Mônica Assis da Silva, Universidade de Caxias do Sul, Brasil Luciana Miranda Costa, Universidade Federal do Pará, Brasil Malena Segura Contrera, Universidade Paulista, Brasil Marcel Vieira Barreto Silva, Universidade Federal da Paraíba, Brasil Maria Ogécia Drigo, Universidade de Sorocaba, Brasil Maria Ataide Malcher, Universidade Federal do Pará, Brasil Maria Clotilde Perez Rodrigues, Universidade de São Paulo, Brasil Maria das Graças Pinto Coelho, Universidade Federal do Rio Grande do Norte, Brasil

Mauricio Ribeiro da Silva, Universidade Paulista, Brasil

Mauro de Souza Ventura, Universidade Estadual Paulista, Brasil Márcio Souza Gonçalves, Universidade do Estado do Rio de Janeiro, Brasil Micael Maiolino Herschmann, Universidade Federal do Rio de Janeiro, Brasil Mirna Feitoza Pereira, Universidade Federal do Amazonas, Brasil Nísia Martins Rosario, Universidade Federal do Rio Grande do Sul, Brasil Potiguara Mendes Silveira Jr, Universidade Federal de Juiz de Fora, Brasil Regiane Ribeiro, Universidade Federal do Paraná, Brasil Rogério Ferraraz, Universidade Anhembi Morumbi, Brasil Rose Melo Rocha, Escola Superior de Propaganda e Marketing, Brasil Rozinaldo Antonio Miani, Universidade Estadual de Londrina, Brasil Sérgio Luiz Gadini, Universidade Estadual de Ponta Grossa, Brasil Simone Maria Andrade Pereira de Sá, Universidade Federal Fluminense, Brasil Veneza Mayora Ronsini, Universidade Federal de Santa Maria, Brasil Walmir Albuquerque Barbosa, Universidade Federal do Amazonas, Brasil

\section{COMISSÃO EDITORIAL}

\section{Cristiane Freitas Gutfreind}

Pontifícia Universidade Católica do Rio Grande do Sul, Brasil

Irene Machado

Universidade de São Paulo, Brasil

Jorge Cardoso Filho

Universidade Federal do Reconcavo da Bahia, Brasil

Universidade Federal da Bahia, Brasil

$$
\begin{aligned}
& \text { REVISÃo DE TEXTOS I Press Revisão } \\
& \text { SECRETÁRIA EXECUTIVA I Helena Stigger } \\
& \text { EDITORAÇÃO ELETRÔNICA I Roka Estúdio }
\end{aligned}
$$

COMPÓS I www.compos.org.br

Associação Nacional dos Programas de Pós-Graduação em Comunicação

Presidente

\section{Eduardo Morettin}

Universidade de São Paulo, Brasil

eduardomorettin@usp.br

\section{Vice-presidente}

Inês Vitorino

Universidade Federal do Ceará, Brasil

ines@ufc.br

Secretária-Geral

Gislene da Silva

Universidade Federal de Santa Catarina, Brasil gislenedasilva@gmail.com 